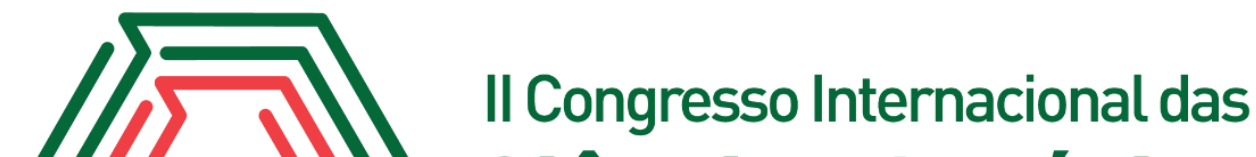 Ciências Agrárias COINTER - PDVAgro 2017
}

\section{A INFLUENCIA DA ASSISTÊNCIA TÉCNICA NA AGRICULTURA FAMILIAR: ENFOQUE NO ASSENTAMENTO MARINGÁ, ARAGUATINS-TO}

\author{
Apresentação: Pôster \\ João Pedro da Luz Milhomem"; Romário Lima de Araújo ${ }^{2}$; Wanderson Lopes de Sousa ${ }^{3}$ \\ Samuel de Deus 4
}

\section{Introdução}

Segundo Lima e Wilkinson (2002). A produção familiar é a principal atividade econômica de diversas regiões brasileiras e precisa ser fortalecida, pois o potencial dos agricultores familiares na geração de empregos e renda é muito importante.

A vários órgãos que auxiliam os agricultores familiares através dos serviços de Assistência Técnica e Extensão Rural (ATER), sendo esses serviços pela Secretaria da Agricultura Familiar (SAF) e Ministério da Agricultura (MDA) (BRASIL, 2004).

Em relação à sua missão, a ATER mais do que simplesmente levar assistência técnica para ampliar a produção, caracterizar-se como uma agência de desenvolvimento capaz de contribuir para despertar o conjunto das energias capazes de fazer do meio rural um espaço propício na luta contra a exclusão social (ABRAMOVAY, 1998).

O objetivo desse presente trabalho foi determinar as propriedades do assentamento Maringá que nunca receberam um acompanhamento técnico, e mostra os benefícios que trás o acompanhamento correto; assim possibilitando uma diminuição do abandono da Agricultura na região de Maringá.

\footnotetext{
${ }^{1}$ Agronomia, IFTO, joaoluzm95@gmail.com

${ }^{1}$ Agronomia, IFTO, romario.ma@hotmail.com

${ }^{1}$ Agronomia, IFTO, wandersonlopes05@hotmail.com

${ }^{1}$ Engenheiro Agrônomo, IFTO, agrosamuel@gmail.com
} 


\section{Fundamentação Teórica}

Os serviços de assistência técnica e extensão rural são essenciais para o desenvolvimento sustentável da agricultura familiar, principalmente, no que se refere a inserção e viabilização de novas práticas agroecológicas. Tal fomento que ainda surge timidamente no cotidiano da agricultura familiar, e precisa de uma abrangência sistêmica e adequada a essa atividade econômica. Todavia é preciso destacar que a ATER envolve desde questões técnicas de manejo e de produção até a educação no campo. (ABRAMOVAY, 2001).

A agricultura familiar possui a capacidade de contribuir ou mesmo de construção de um componente de projeto nacional de desenvolvimento sustentável. Pesquisas realizadas por Mussoi et al (2003), destacam quatro expressões da multifuncionalidade da agricultura familiar: Garante reprodução socioeconômica das famílias rurais; Promove a segurança alimentar das próprias famílias e da sociedade; Mantém o tecido social e cultural; Preservação dos recursos naturais e da paisagem rural.

As técnicas e tecnologias agrícolas sustentáveis costumam chegar até o agricultor por meio de assistência técnica e extensão rural, a assistência técnica sozinha não se configura em fator determinante, único e soberano para o desenvolvimento ou não de uma área de assentamento ou mesmo de uma comunidade rural, (FATORELLI \& MERTENS, 2010, p.406).

Fatorelli \& Mertens (2010) descrevem que há situações (como a falta de planejamento antes de se criar o assentamento, a escassez de infraestrutura, a falta de interesse do próprio agricultor, dentre outros), onde a simples presença da assistência técnica não poderia resolver essa situação pretérita de organização social e infraestrutura precária, carecendo da atuação do poder público para a resolução desses problemas estruturantes antes que o trabalho da mesma surta efeitos práticos.

\section{Metodologia}

O assentamento Maringá esta localizado no município de Araguatins-TO, Possui uma área total de 3.279,1554 hectares e sua área de reserva legal é de 968,0000 hectares. As cidades mais próximas ao Assentamento Maringá são as cidades de Araguatins, distante 26 quilômetros do Assentamento; e a cidade de Buriti do Tocantins, localizada a 20 quilômetros de distância. Araguatins possuindo cerca de 18 assentamentos em seu entorno.

Segundo Souza (2009). O P.A Maringá possui um grande número de pequenos agricultores, 
pequenos proprietários, apicultores, bem como extrativistas que sobrevivem da coleta de coco babaçu, frutas e da pesca artesanal.

Com relação aos produtos como o arroz, feijão, milho e pequenos animais, são produzidos somente para fins de subsistência, raramente comercializado o excedente, em função dos preços pouco atrativos, embora que no passado a produção de arroz tenha sido bastante comercializado. Destaca - se a produção de mandioca, pois assim como os demais, ela é produzida pela maioria dos agricultores, constitui a base econômica das famílias e é definida como uma das cadeias produtivas de importância econômica para o território, notando-se imensa importância econômica, social, ambiental e cultural.

\section{Resultados e Discussões}

Através de conversas informais, constatou-se que a maioria dos agricultores familiares produzem os alimentos básicos para subsistência, sendo a atividade econômica principal, os principais produtos são: milho, mandioca, arroz e feijão; apicultura e extrativismo especialmente frutas nativas, pequenos animais; babaçu, bovinocultura, pesca artesanal.

Os produtores relataram que poucos recebem ou receberam assistência técnica, mas foi observado que quem recebeu assistência, ouvi aumento significativo na produção. A maioria dos produtores tem interesse em receber assistência, mas muitos estão desacreditados em alguém técnicos pela falta de acompanhamento correto, ou por não demostrarem confiança no que dizem isso mostra que deve haver uma melhor capacitação dos mesmos.

Podemos observar em pesquisas realizadas através de entrevistas feitas no assentamento com produtores, que á falta de incentivo dos filhos em seguirem a atividade dos pais são devidas poucas opções de geração de renda, isso é provocado por diversos fatores e um deles é a falta de acompanhamento técnico de um profissional no assentamento.

Podemos observar que o serviço de assistência técnica pode atrair mais clientes para quem possui, sendo visto como um atributo favorável para o produtor, pois quem recebe um acompanhamento correto com profissionais, produz produtos de qualidade, melhor rendimento, produtos livres de patógenos, peso e tamanho ideal, tudo isso a gosto do consumidor.

Com isso podemos observar que a assistência técnica possui papel fundamental para a permanência do homem do campo, no campo com qualidade. Através do acompanhamento há maior produtividade, consequentemente melhor qualidade de vida dos assentados. Uns dos maiores 
empecilhos encontradas pela maioria dos assentados é baixa fertilidade do solo, os mesmos relatam que nunca fizeram analise do solo em suas propriedades, consequentemente nenhum tipo de correção é realizada nessa comunidade.

O manejo inadequado de pragas, sem a orientação correta, também é um dos agravantes enfrentados pelos assentados do P.A Maringá, que sofrem com ataques de diversas pragas em suas lavouras, que com falta de assistência técnica acaba se agravando muito mais fazendo com que o produtor acaba até desistindo da atividade agrícola ou pecuária.

\section{Conclusões}

Com este trabalho foi possível constatar que a Assistência Técnica é capaz de contribuir para o desenvolvimento sustentável não só no assentamento Maringá, mas em qualquer comunidade que tenha interesse de desenvolver sua região e aumentar ou complementar sua renda.

A pouca ou nada assistência recebida pelos assentados é um dos maiores empecilho na produção agrícola, juntamente com a falta de incentivo financeiro do governo, que acaba burocratizando e dificultando o acesso ao credito, com isso os assentados acabam não tento condições necessárias para permanência da atividade exercida, havendo uma migração para os grandes centros, a procura de empregos.

\section{Referências}

ABRAMOVAY, R. O capital social dos territórios: repensando o desenvolvimento rural. In Anais do Seminário Reforma Agrária e Desenvolvimento Sustentável, Brasília: Paralelo 15/NEAD/MDA, 2001.

BRASIL/MDA - Ministério do Desenvolvimento Agrário. Política Nacional de Assistência Técnica e Extensão Rural. Brasília: MDA/SAF/Dater, 2004.

FATORELLI, L. \& MERTENS, F. Integração de políticas e governança ambiental: o caso do licenciamento rural no Brasil. Ambiente \& Sociedade, Campinas/SP, v. 13, n. 2, p. 401-415, dez. 2010.

LIMA, Dalmò M de Albuquerque e WILKINSON, John (orgs). Inovação nas tradições da agricultura familiar. Brasília: CNPq/Paralelo 15, 2002.

MUSSOI, E. M. Políticas públicas para o rural em Santa Catarina: descontinuidades na continuidade. In: PAULILO, Maria Ignez S.; SCHMIDT, Wilson. (org.) Agricultura e espaço rural em Santa Catarina. Florianópolis: Ed. da UFSC, 2003. p. 211-235. 
assentamentos do bico do papagaio. DISSERTAÇÃO, Seropédica, RJ Abril/2009. 